\title{
Eficácia do fungicida epoxiconazol aplicado via pivô central no feijoeiro'
}

João P. A. R. da Cunha ${ }^{2}$, Mauri M. Teixeira ${ }^{3}$, Rogério F. Vieira ${ }^{4}$ \& Luiz C. de A. Barbosa ${ }^{5}$

\author{
1 Parte da Dissertação de Mestrado do primeiro autor \\ 2 DEA/UFV, CEP 36571-000, Viçosa, MG. E-mail: jparc@bol.com.br (Foto) \\ 3 DEA/UFV. E-mail: mauri@mail.ufv.br \\ ${ }^{4}$ EPAMIG/EMBRAPA. E-mail: rfvieira@mail.ufv.br \\ 5 DEQ/UFV. E-mail: Icab@mail.ufv.br
}

Protocolo $149-11 / 12 / 2000$

\begin{abstract}
Resumo: No Brasil, a fungigação na cultura do feijão vem sendo empregada pelos agricultores desde o início de 1980, porém ainda são poucos os trabalhos desenvolvidos para avaliar a eficiência desta técnica. Assim, com o presente trabalho objetivou-se avaliar a eficácia do fungicida epoxiconazol, aplicado via água de irrigação no controle de doenças da parte aérea do feijoeiro, nos sistemas de plantio convencional e direto e avaliar o efeito da lâmina de água na eficiência da fungigação. Aplicou-se o fungicida epoxiconazol via pivô central na cultura do feijão, nos plantios direto e convencional, em diferentes lâminas de água $(3,5$ e $7 \mathrm{~mm}$ ) avaliando-se a severidade de doenças em parcelas tratadas e não-tratadas. Para comparação, o produto também foi aplicado de forma convencional (pulverizador costal a pressão constante). Os resultados alcançados permitiram afirmar que o fungicida epoxiconazol, aplicado via pivô central, reduziu a severidade da mancha angular e da mancha de alternária do feijoeiro; e as lâminas de água utilizadas na fungigação não influenciaram a eficácia do fungicida epoxiconazol.
\end{abstract}

Palavras-chave: quimigação, tecnologia de aplicação, doenças do feijoeiro, Phaseolus vulgaris L.

\section{Efficacy of the fungicide epoxiconazol applied by center pivot irrigation system on dry bean}

\begin{abstract}
The fungigation of bean crops have been used in Brazil by the agriculturists since the beginning of the 1980's. However, few surveys have been conducted to evaluate the efficiency of this technique. Thus, the objectives of this work were to evaluate the efficacy of the fungicide epoxiconazol, applied through irrigation water, for the control of diseases in bean crops, under conventional and no-till systems; as well as to study the influence of depth of applied water on the fungigation efficiency. The fungicide epoxiconazol was applied on the bean crops, under conventional and no-till systems, by a center pivot system with different depths of applied water $(3,5$ and $7 \mathrm{~mm})$, and disease severity was evaluated for each test. The efficiency of the fungicide application by a conventional system (compression knapsack sprayer) was also evaluated. The results obtained allow us to affirm that the fungicide epoxiconazol, applied by a center pivot system, decreased the severity of bean angular leaf spot and bean alternaria leaf spot; and the depth of applied water by fungigation did not influence the efficacy of the fungicide epoxiconazol.
\end{abstract}

Key words: chemigation, application technology, bean diseases, Phaseolus vulgaris L.

\section{INTRODUÇ̃̃O}

O aumento da população mundial tem exigido, da agricultura, cada vez mais eficiência e competitividade. Nesse contexto, o controle de pragas, de doenças e de plantas daninhas nas áreas de plantio, tornou-se uma preocupação constante do agricultor.

Dentre as diferentes técnicas de aplicação de defensivos agrícolas disponíveis, as que se baseiam na pulverização convencional do produto (costal e tratorizada) são as mais difundidas, graças à flexibilidade que oferecem em distintas aplicações. Atualmente, entretanto, uma nova técnica de aplicação fitossanitária, a quimigação, vem-se desenvolvendo bastante. A aplicação de produtos químicos na lavoura por intermédio da água de irrigação está se intensificando junto aos produtores que dispõem de equipamentos de irrigação, pois é técnica eficiente para muitos produtos, além de economicamente viável.

Os sistemas de irrigação por aspersão são os mais adequados para o uso dessa técnica, por apresentarem alto coeficiente de uniformidade de distribuição de água, quando 
manejados adequadamente e, sobretudo, por constituírem o único método que permite o controle de doenças foliares.

Produtores rurais já fazem uso dessa técnica, mas sem o devido respaldo da pesquisa. Muitos produtores, por sua conta e risco, baseados em suas próprias observações, estão fazendo aplicações de produtos como fungicidas e inseticidas, sem o conhecimento dos riscos ambientais que a nova técnica, quando utilizada de maneira inadequada, pode acarretar.

Dentro desse contexto, a cultura do feijão representa importante atividade agrícola no Brasil, principalmente quando se leva em conta que esta leguminosa é produzida por pequenos e médios agricultores. As doenças que ocorrem nesta cultura constituem uma das principais causas da sua baixa produtividade no Brasil. Muitas doenças, dentre elas as causadas por fungos, podem ocasionar perdas totais ou inviabilizar determinadas áreas para o plantio (Paula Jr. \& Zambolim, 1998). Uma alternativa para sanar o problema é a aplicação de fungicidas, seja ela feita da forma convencional ou via água de irrigação (fungigação). Os fungicidas diminuem a severidade das doenças e aumentam o rendimento da cultura (Dudienas et al., 1990). Esses fungicidas, assim como sua forma de aplicação, devem estar registrados junto ao órgão federal competente.

No Brasil, a fungigação na cultura do feijão vem sendo empregada pelos agricultores há alguns anos, mas poucos são os trabalhos desenvolvidos para se avaliar sua eficiência (Sartorato \& Rava, 1998). Especialmente no feijoeiro, a fungigação parece bastante promissora, pois o fechamento da cultura a partir do florescimento torna difícil a entrada de máquinas na lavoura para o controle de doenças.

Por outro lado, a principal dúvida com relação à fungigação está relacionada ao grande volume de água utilizado. A diluição do fungicida pode afetar a eficácia do produto, reduzindo o controle de doenças.

Vieira \& Sumner (1999) citam alguns pontos favoráveis à fungigação, que compensam o potencial de lavagem provocado pelo grande volume de água utilizado, permitindo bom controle das doenças: aplicação do fungicida no momento de maior atividade do fungo, melhor uniformidade de distribuição, cobertura quase completa de todo o dossel das plantas e redução de inóculo na lavoura. Além disso, os fungicidas, quando aplicados na água de irrigação, proporcionam melhor controle de patógenos do solo, menores danos mecânicos à cultura e menor compactação do solo, propiciando um rendimento da cultura equivalente ou superior àquele obtido com a pulverização convencional.

Segundo Vieira \& Sumner (1999), o que se percebe nos trabalhos publicados, comparando-se a fungigação e a aplicação convencional, é que esta se mostra ligeiramente superior na redução da severidade de doenças, porém os rendimentos são equivalentes.

O mofo-branco (Sclerotinia sclerotiorum) é a doença mais estudada quanto ao uso da fungigação no feijoeiro (Vieira \& Silva, 1998). Oliveira et al. (1995) afirmam que a fungigação é uma técnica viável para o controle do mofo-branco no feijoeiro, proporcionando eficiência equivalente ou superior à técnica convencional. Já com relação à ferrugem (Uromyces appendiculatus) Pinto et al. (1990) utilizando o fungicida sistêmico bitertanol aplicado por aspersores setoriais em lâminas de $3 \mathrm{~mm}$, verificaram redução da severidade da doença. Também Oliveira et al. (1992a) avaliando a eficácia de fungicidas aplicados via pivô central no controle da ferrugem, do mofo-branco e da mancha angular (Phaeoisariopsis griseola) constataram redução da intensidade de doenças, quando comparada à testemunha, mas o tratamento convencional se mostrou superior à fungigação no controle da mancha angular.

Oliveira et al. (1992b) comparando a fungigação e a aplicação convencional de fungicida no controle do oídio (Erysiphe polygoni) e da mancha de alternária (Alternária spp.) concluíram que, de maneira geral, a fungigação se mostrou melhor que o método convencional no controle do oídio, resultando em maior produtividade.

Desta forma, o presente trabalho teve, como objetivo, avaliar a eficácia do fungicida epoxiconazol, aplicado via água de irrigação, no controle de doenças da parte aérea do feijoeiro, nos sistemas de plantio convencional e direto e, também, avaliar o efeito da lâmina de água na eficiência da fungigação.

\section{MATERIAL E MÉTODOS}

Este trabalho foi desenvolvido em condições de campo, durante a estação de inverno do ano de 1999, em área experimental da Universidade Federal de Viçosa, município de Coimbra, MG, na altitude de $716 \mathrm{~m}$, longitude de $42^{\circ} 48^{\prime} \mathrm{S}$ e latitude de $20^{\circ} 51^{\prime} \mathrm{W}$.

Utilizou-se a cultivar de feijão do tipo carioca Pérola, semeada no espaçamento entre fileiras de $0,45 \mathrm{~m}$, com cerca de 15 sementes $\mathrm{m}^{-1}$. A cultivar Pérola foi lançada em 1996 ocupando, atualmente, quase $70 \%$ da área plantada do País. É de grande adaptação (indicada para 11 estados brasileiros), possui boa qualidade industrial e possibilita a colheita mecânica.

Suas principais características são:

- origem: CNPAF/Embrapa

- floração média: $46 \mathrm{~d}$

- ciclo de vida: 85-90 d

- massa média de 100 sementes: $27 \mathrm{~g}$

- Reação a doenças: resistente ao vírus-do-mosaico-comum (BCMV) e à ferrugem. Em condições de campo, é moderadamente resistente à murcha-de-fusarium e à mancha angular. Possui resistência à raça alfa-Brasil TUS (TU suscetível) e suscetibilidade às raças alfa-Brasil capa e zeta de Colletotrichum lindemuthianum, agente causador da antracnose.

O fungicida utilizado para o controle das doenças da parte aérea foi o epoxiconazol na dosagem de $100 \mathrm{~mL} \mathrm{ha}^{-1}$ do produto comercial. Trata-se de um fungicida sistêmico, com as seguintes características:

- grupo químico: triazóis

- fórmula molecular: $\mathrm{C}_{17} \mathrm{H}_{13} \mathrm{Cl} \mathrm{F} \mathrm{N}_{3} \mathrm{O}$

- formulação: suspensão concentrada

- concentração: $125 \mathrm{~g} \mathrm{~L}^{-1}$

- toxicidade: classe I

- solubilidade em água determinada a $20^{\circ} \mathrm{C}: 7,05 \mathrm{mg} \mathrm{L}^{-1}$

O produto foi aplicado três vezes, a intervalo de $14 \mathrm{~d}$, a partir de $45 \mathrm{~d}$ após a emergência, via água de irrigação e de forma convencional, mantendo-se a mesma dosagem. No 
controle convencional, ele foi aplicado com pulverizador costal de pressão constante $\left(\mathrm{CO}_{2}\right)$ utilizando-se pontas de pulverização do tipo cone vazio, conforme recomendação de Blanca (1997) com volume de calda de $300 \mathrm{~L} \mathrm{ha}^{-1}$ e pressão de $400 \mathrm{kPa}$.

A injeção do fungicida na água de irrigação foi realizada utilizando-se uma bomba hidráulica do tipo diafragma, com capacidade de injeção de $10 \mathrm{a} 250 \mathrm{~L} \mathrm{~h}^{-1} \mathrm{e}$ o sistema de irrigação foi do tipo aspersão por pivô central. Utilizou-se um pivô de média pressão, dotado de aspersores, cobrindo uma área de três hectares.

O manejo da irrigação foi monitorado através do Sistema de Suporte à Decisão Agrícola (SISDA) programa computacional desenvolvido pelo Departamento de Engenharia Agrícola da Universidade Federal de Viçosa. Durante as aplicações de fungicida, monitoraram-se as condições ambientais e a uniformidade de aplicação de água.

\section{Eficácia do fungicida no controle de doenças da parte aérea}

A avaliação da eficácia do fungicida no controle das doenças da parte aérea do feijoeiro foi feita mediante a comparação da severidade de doenças entre parcelas tratadas com fungicida (fungigação e aplicação convencional) e parcelas não-tratadas (testemunha). As parcelas submetidas ao tratamento convencional e as testemunhas foram cobertas durante as fungigações.

A avaliação da severidade de doenças nas folhas observadas naturalmente no campo, foi realizada a partir do aparecimento dos primeiros sintomas e, depois, a intervalos de sete dias, totalizando três avaliações. Para isto, utilizaram-se as escalas diagramáticas propostas por Godoy et al. (1997). Estas escalas, específicas para as doenças do feijoeiro, levam em conta o mínimo e o máximo de sintomas encontrados no campo, representando os sintomas da forma mais próxima possível do observado nas plantas e com níveis intermediários que consideram as limitações da acuidade visual humana. Ressalta-se que, na avaliação, marcaram-se 10 plantas, escolhidas ao acaso em cada parcela e, em cada planta, três folhas: uma na parte inferior, outra na parte intermediária e a terceira na parte superior da planta. A avaliação da severidade de doenças nas folhas foi feita aos 70, 77 e 84 d após a emergência. Avaliou-se, também, a população final de plantas, a produtividade e a massa de 100 sementes, por ocasião da colheita. $\mathrm{O}$ ciclo de vida da cultura do feijão foi de $112 \mathrm{~d}$.

A população final de plantas, expressa em número de plantas por hectare, foi estimada contando-se o número de plantas na área útil de cada parcela e a produtividade da cultura foi estimada pesando-se os grãos colhidos nas parcelas experimentais, transformando-se os dados para $\mathrm{kg} \mathrm{ha}^{-1}$, a $12 \%$ de umidade (b.u.).

\section{Influência da lâmina de água na fungigação}

As aplicações de fungicida via água de irrigação foram feitas nas seguintes lâminas de água: 3,5 e $7 \mathrm{~mm}$, para o que se variou o percentímetro do pivô central, mantendo-se constante a quantidade de fungicida aplicado por área.

\section{Influência do sistema de cultivo no controle de doenças}

A área irrigada pelo pivô central foi dividida em duas partes, uma para o sistema de plantio convencional (P.C.) e a outra para o sistema de plantio direto (P.D.) (Figura 1).

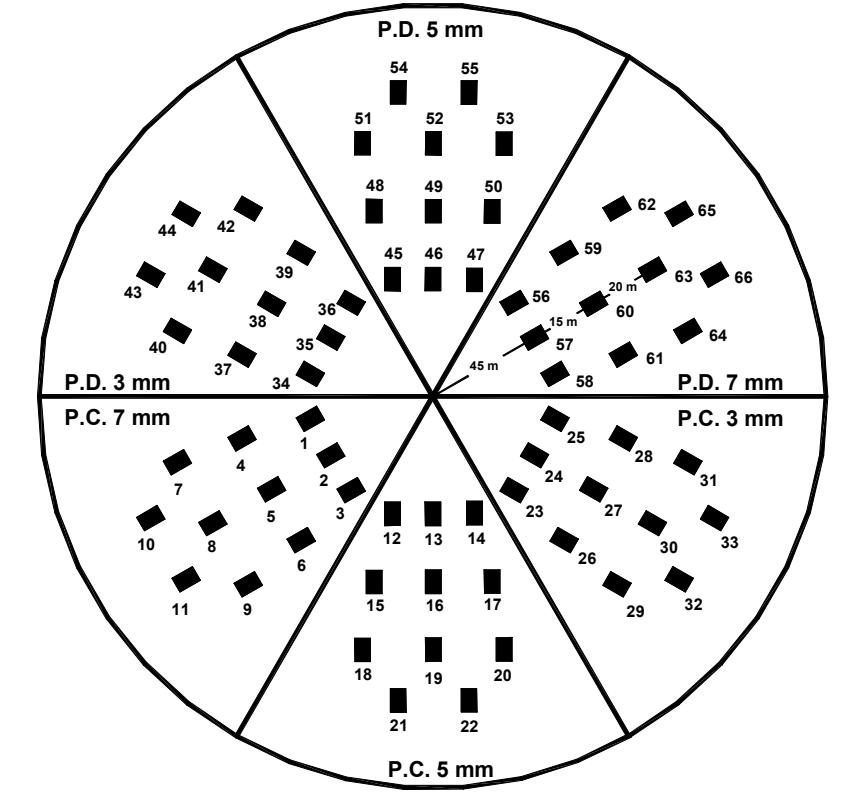

\begin{tabular}{|c|c|c|c|c|}
\hline \multirow[b]{2}{*}{ PARCELAS } & \multicolumn{4}{|c|}{ FATORES EM ESTUDO } \\
\hline & $\begin{array}{l}\text { Método de } \\
\text { aplicação }\end{array}$ & $\begin{array}{c}\text { Sistema de } \\
\text { cultivo }\end{array}$ & Posição & Lâmina \\
\hline $1,2,3$ & \multirow{18}{*}{ Fungigação } & \multirow{9}{*}{$\begin{array}{c}\text { Plantio } \\
\text { convencional }\end{array}$} & 1 & \multirow{3}{*}{$7 \mathrm{~mm}$} \\
\hline $4,5,6$ & & & 2 & \\
\hline $7,8,9$ & & & 3 & \\
\hline $12,13,14$ & & & 1 & \multirow{3}{*}{$5 \mathrm{~mm}$} \\
\hline $15,16,17$ & & & 2 & \\
\hline $18,19,20$ & & & 3 & \\
\hline $23,24,25$ & & & 1 & \multirow{3}{*}{$3 \mathrm{~mm}$} \\
\hline $26,27,28$ & & & 2 & \\
\hline $29,30,31$ & & & 3 & \\
\hline $34,35,36$ & & \multirow{9}{*}{$\begin{array}{c}\text { Plantio } \\
\text { direto }\end{array}$} & 1 & \multirow{3}{*}{$3 \mathrm{~mm}$} \\
\hline $37,38,39$ & & & 2 & \\
\hline $40,41,42$ & & & 3 & \\
\hline $45,46,47$ & & & 1 & \multirow{3}{*}{$5 \mathrm{~mm}$} \\
\hline $48,49,50$ & & & 2 & \\
\hline $51,52,53$ & & & 3 & \\
\hline $56,57,58$ & & & 1 & \multirow{3}{*}{$7 \mathrm{~mm}$} \\
\hline $59,60,61$ & & & 2 & \\
\hline $62,63,64$ & & & 3 & \\
\hline $10,21,32$ & \multirow{2}{*}{ Convencional } & $\begin{array}{c}\text { Plantio } \\
\text { convencional }\end{array}$ & - & - \\
\hline $43,54,65$ & & $\begin{array}{c}\text { Plantio } \\
\text { direto }\end{array}$ & - & - \\
\hline $11,22,33$ & \multirow{2}{*}{ Sem aplicação } & $\begin{array}{c}\text { Plantio } \\
\text { convencional }\end{array}$ & - & - \\
\hline $44,55,66$ & & $\begin{array}{l}\text { Plantio } \\
\text { direto }\end{array}$ & - & - \\
\hline
\end{tabular}

Figura 1. Disposição das parcelas no campo experimental

O preparo do solo na semeadura convencional do feijão foi feito com uma aração e duas gradagens. A adubação foi realizada utilizando-se $700 \mathrm{~kg} \mathrm{ha}^{-1}$ da fórmula 4-14-8, no plantio, e $45 \mathrm{~kg} \mathrm{ha}^{-1}$ de nitrogênio em cobertura, na forma de uréia, aos $23 \mathrm{~d}$ após a emergência.

Realizou-se o controle de plantas daninhas e de insetos usando-se defensivos químicos: herbicida metolaclor em pré-emergência, na dosagem de $2,5 \mathrm{~L} \mathrm{ha}^{-1}$, aplicado via pivô central na lâmina de água média de $10 \mathrm{~mm}$; herbicida fomesafen em pós-emergência, na dosagem de $0,9 \mathrm{~L} \mathrm{ha}^{-1}$, aplicado via pivô central na lâmina de água média de $6 \mathrm{~mm}$ e inseticida deltamethrine, na dosagem de $150 \mathrm{~mL} \mathrm{ha}^{-1}$, aplicado via pivô central na lâmina média de $6 \mathrm{~mm}$. 
No plantio direto, realizou-se a semeadura sobre restos de cultura do milho, após a aplicação do herbicida glifosato, além da mesma adubação e dos mesmos defensivos usados no plantio convencional.

A parcela experimental foi de $5,4 \mathrm{~m}^{2}(3 \times 1,8 \mathrm{~m})$ constituída de quatro fileiras de $3 \mathrm{~m}$ de comprimento, espaçadas $0,45 \mathrm{~m}$. Os dados de severidade de doenças, produtividade, massa de 100 sementes e população final de plantas, foram analisados por meio de estatística descritiva, determinando-se as médias e os erros-padrão.

\section{RESULTADOS E DISCUSSÃO}

A temperatura, a umidade relativa do ar e a velocidade do vento foram, durante as aplicações do fungicida, favoráveis à aplicação de defensivos químicos: temperatura inferior a $28^{\circ} \mathrm{C}$, umidade relativa superior a $60 \%$ e velocidade do vento menor que $3 \mathrm{~m} \mathrm{~s}^{-1}$. A uniformidade de distribuição de água, representada pelo Coeficiente de Uniformidade de Christiansen (CUC) e determinada durante as operações de fungigação, foi de $87 \%$ para a primeira aplicação, de $84 \%$ para a segunda e de $88 \%$ para a terceira, encontrando-se dentro dos padrões aceitáveis para sistemas de irrigação do tipo pivô central.

A mancha angular e a mancha de alternária foram as doenças que atacaram o feijoeiro com maior severidade. Em algumas áreas isoladas também houve pequena incidência de antracnose, ressaltando-se que as maiores severidades da mancha angular e da mancha de alternária foram verificadas no final do ciclo de vida da cultura, em parcelas de plantio direto que não receberam fungicida e as menores severidades foram constatadas na primeira avaliação, em parcelas de plantio convencional que receberam a aplicação convencional de fungicida.
Eficiência dos métodos de aplicação no controle de doenças

Os resultados referentes à eficiência dos métodos de aplicação de fungicida convencional (pulverizador costal a pressão constante) e fungigação, são apresentados nas Tabelas 1 e 2, observando-se, na Tabela 1, que a mancha angular e a mancha de alternária ocorreram em intensidade leve a moderada. Apesar disso, foram constatadas diferenças entre as parcelas tratadas com fungicida e as não-tratadas. Ocorreu aumento da severidade das doenças com o avanço do ciclo de vida da cultura.

As duas formas de aplicação de fungicida reduziram a severidade da mancha angular. A aplicação convencional reduziu a área foliar afetada pela mancha angular, de 4,51 para $0,49 \%$, na média das três avaliações, quando comparada com a testemunha; a fungigação reduziu-a de 4,51 para $0,97 \%$.

Para a mancha de alternária, a redução da severidade proporcionada pelo fungicida aplicado pelo método convencional foi de 5,83 para 1,29\% e nas parcelas submetidas à fungigação, a redução foi de 5,83 para 1,82\%.

A aplicação convencional mostrou-se ligeiramente superior à fungigação na redução da severidade das duas doenças, mas as produtividades da cultura obtidas com essas duas formas de aplicação foram equivalentes.

De maneira geral, os dois métodos de aplicação do fungicida epoxiconazol resultaram em bom controle das duas doenças. Rocha et al. (1999) avaliando o epoxiconazol na mesma dosagem de ingrediente ativo $\left(12,5 \mathrm{~g} \mathrm{ha}^{-1}\right)$ aplicado com pulverizador costal a $\mathrm{CO}_{2}$, no controle de doenças na cultura do feijão, também demonstraram que ele controlou eficazmente a mancha angular, sem fitotoxicidade para a cultura. Quanto à eficácia deste fungicida via água de irrigação, não se encontraram trabalhos a esse respeito na literatura.

A população final de plantas variou de 20 a 22 plantas $\mathrm{m}^{-2}$ (Tabela 2) ou seja, de 204 a 217 mil plantas ha ${ }^{-1}$, situando-se

Tabela 1. Efeito do método de aplicação de fungicida no controle da mancha angular (A) e da mancha de alternária (B) do feijoeiro

\begin{tabular}{|c|c|c|c|c|c|c|}
\hline \multirow{3}{*}{ Método de Aplicação } & \multicolumn{6}{|c|}{ Área Foliar Afetada - \% } \\
\hline & \multicolumn{2}{|c|}{ 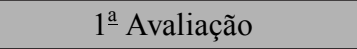 } & \multicolumn{2}{|c|}{$2^{\mathrm{a}}$ Avaliação } & \multicolumn{2}{|c|}{$3^{3}$ Avaliação } \\
\hline & Média & Erro-padrão & Média & Erro-padrão & Média & Erro-padrão \\
\hline \multicolumn{7}{|c|}{ A. Avaliação da severidade da mancha angular* } \\
\hline Fungigação & 0,44 & 0,05 & 0,92 & 0,04 & 1,56 & 0,13 \\
\hline Aplicação convencional & 0,20 & 0,05 & 0,40 & 0,06 & 0,87 & 0,08 \\
\hline Testemunha & 3,15 & 0,37 & 4,37 & 0,42 & 6,00 & 0,33 \\
\hline \multicolumn{7}{|c|}{ B. Avaliação da severidade da mancha de alternária* } \\
\hline Fungigação & 1,07 & 0,29 & 2,04 & 0,27 & 2,35 & 0,35 \\
\hline Aplicação convencional & 0,75 & 0,17 & 1,28 & 0,08 & 1,85 & 0,29 \\
\hline Testemunha & 4,42 & 0,42 & 6,00 & 0,25 & 7,08 & 0,55 \\
\hline
\end{tabular}

* A primeira avaliação foi feita aos $70 \mathrm{DAE}$, a segunda aos 77 DAE e a terceira aos 84 DAE

Tabela 2. Efeito do método de aplicação de fungicida na população final de plantas por parcela*, massa de 100 sementes e produtividade do feijoeiro

\begin{tabular}{|c|c|c|c|c|c|c|}
\hline \multirow{2}{*}{ Método de Aplicação } & \multicolumn{2}{|c|}{ População Final } & \multicolumn{2}{|c|}{$\begin{array}{l}\text { Massa de } 100 \text { Sementes** } \\
(\mathrm{g})\end{array}$} & \multicolumn{2}{|c|}{$\begin{array}{l}\text { Produtividade** } \\
\qquad\left(\mathrm{kg} \mathrm{ha}^{-1}\right)\end{array}$} \\
\hline & Média & $\begin{array}{c}\text { Erro-padrão } \\
\text { da média }\end{array}$ & Média & $\begin{array}{c}\text { Erro-padrão } \\
\text { da média }\end{array}$ & Média & $\begin{array}{c}\text { Erro-padrão } \\
\text { da média }\end{array}$ \\
\hline Fungigação & 110 & 3,66 & 26,34 & 1,30 & 2.199 & 79,62 \\
\hline Aplicação convencional & 117 & 5,07 & 27,02 & 0,88 & 2.235 & 56,16 \\
\hline Testemunha & 114 & 5,47 & 24,91 & 0,26 & 2.004 & 47,30 \\
\hline
\end{tabular}

* Parcela de tamanho $5,4 \mathrm{~m}^{2}$

** Sementes com $12 \%$ de umidade (b.u.) 
Tabela 3. Efeito da lâmina de água utilizada durante a fungigação no controle da mancha angular (A) e da mancha de alternária (B) do feijoeiro

\begin{tabular}{|c|c|c|c|c|c|c|}
\hline \multirow{3}{*}{ Método de aplicação } & \multicolumn{6}{|c|}{ Área Foliar Afetada - \% } \\
\hline & \multicolumn{2}{|c|}{$1^{\mathrm{a}}$ Avaliação* } & \multicolumn{2}{|c|}{$2^{-a}$ Avaliação* } & \multicolumn{2}{|c|}{$3^{\mathrm{a}}$ Avaliação* } \\
\hline & Média & Erro-padrão & Média & Erro-padrão & Média & Erro-padrão \\
\hline \multicolumn{7}{|l|}{ A. Mancha Angular } \\
\hline Lâmina (3 mm) & 0,48 & 0,04 & 0,91 & 0,04 & 1,57 & 0,09 \\
\hline Lâmina (5 mm) & 0,43 & 0,05 & 0,88 & 0,03 & 1,58 & 0,11 \\
\hline Lâmina (7 mm) & 0,40 & 0,06 & 0,97 & 0,05 & 1,54 & 0,18 \\
\hline Testemunha & 3,15 & 0,37 & 4,37 & 0,42 & 6,00 & 0,33 \\
\hline \multicolumn{7}{|l|}{ B. Mancha de Alternária } \\
\hline Lâmina (3 mm) & 1,08 & 0,25 & 1,97 & 0,26 & 2,28 & 0,40 \\
\hline Lâmina (5 mm) & 1,04 & 0,32 & 2,00 & 0,26 & 2,31 & 0,27 \\
\hline Lâmina (7 mm) & 1,08 & 0,31 & 2,14 & 0,29 & 2,47 & 0,39 \\
\hline Testemunha & 4,42 & 0,42 & 6,00 & 0,25 & 7,08 & 0,55 \\
\hline
\end{tabular}

* A primeira avaliação foi feita aos 70 DAE, a segunda aos 77 DAE e a terceira aos 84 DAE

dentro da faixa recomendada para a cultura do feijão (Vieira, 1978). A massa de 100 sementes variou de 24,91 a $27,02 \mathrm{~g}$. As parcelas tratadas com fungicida (aplicação convencional e fungigação) proporcionaram, em média, uma massa 7,11\% superior à da testemunha, o que demonstra ser a massa das sementes um dos componentes da produtividade influenciados positivamente pelo controle de doenças.

A produtividade das parcelas tratadas com fungicida foi $10,6 \%$ superior em relação à testemunha. Provavelmente, se a infecção fosse mais severa e mais precoce, haveria maiores diferenças de produtividade entre parcelas tratadas e nãotratadas. Alguns fungicidas, além de controlarem doenças, retardam a senescência das folhas, permitindo maior atividade fotossintética e, conseqüentemente, maior produtividade.

\section{Efeito do sistema de cultivo na ocorrência de doenças}

Analisando-se os dados das testemunhas, percebeu-se severidade leve a moderada da mancha angular e da mancha de alternária, tanto em plantio direto como em plantio convencional. Por se tratar do primeiro plantio direto de feijão na área experimental, não havia restos culturais de feijão infectados com doenças na superfície do solo. Os problemas fitossanitários geralmente se agravam a partir do segundo ano de cultivo consecutivo. No sistema de plantio direto, os restos culturais são deixados na superfície do solo, aumentando o período de sobrevivência de alguns patógenos e acarretando maior severidade de doenças na safra seguinte, se o planejamento de rotação de culturas não for adequado. Doenças como a mancha angular e a mancha de alternária têm, nos restos de cultura, seu principal meio de sobrevivência (Vieira \& Paula Jr., 1998).

\section{Efeito da lâmina de água na eficiência da fungigação}

Os resultados referentes à influência das lâminas de água utilizadas durante a aplicação do fungicida sobre o controle da mancha angular e da mancha de alternária, são apresentados na Tabela 3.

A severidade da mancha angular, observada durante a primeira avaliação nas diferentes lâminas de fungigação, variou de 0,40 a $0,48 \%$, na segunda de 0,88 a $0,97 \%$ e na terceira de 1,54 a $1,58 \%$. Para a mancha de alternária, na primeira avaliação a severidade variou de 1,04 a $1,08 \%$, na segunda de 1,97 a 2,14\% e na terceira de 2,28 a 2,47\%. Esses resultados demonstram que as lâminas de 3, 5 e 7 mm não influenciaram o desempenho do fungicida epoxiconazol, aplicado via água de irrigação, no controle das duas doenças. A aplicação do fungicida nas três lâminas de água controlou as duas doenças, quando comparada com a testemunha. Vieira \& Sumner (1999) mostram que a queda de efíciência da fungigação se dá, de maneira geral, com lâminas de água superiores a $8 \mathrm{~mm}$.

Geralmente, os triazóis são de rápida absorção, tanto foliar como por parte da raiz, e isto pode ter compensado o potencial de lavagem provocado pelo alto volume de água, resultado concordante com os dados apresentados por Pinto \& Costa (1992). Avaliando o efeito da lâmina de água na aplicação do fungicida hidróxido de trifenil estanho via aspersão convencional para o controle da brusone (Pyricularia oryzae) em arroz, esses autores verificaram não haver diferença na produção de grãos com as lâminas de 3, 6 e $9 \mathrm{~mm}$.

\section{CONCLUSÕES}

Os resultados permitiram enumerar as seguintes conclusões:

1. O fungicida epoxiconazol, aplicado via pivô central, reduziu a severidade da mancha angular e da mancha de alternária do feijoeiro.

2. As lâminas de água utilizadas na fungigação não influenciaram a eficácia do fungicida epoxiconazol.

\section{LITERATURA CITADA}

Blanca, A.L. Maquinaria agrícola. Madrid: Mundi-prensa, 1997. $361 p$.

Dudienas, C.; Castro, J.L.; Ito, M.F.; Soave, J.; Maeda, J.A. Efeito de fungicidas na produção, sanidade e qualidade fisiológica de sementes de feijão. Fitopatologia Brasileira, Brasília, v.15, n.1, p.20-24, 1990.

Godoy, C.V.; Carneiro, S.M.T.P.G.; Iamauti, M.T.; Dalla Pria, M.; Amorim, L.; Berger, R.D.; Bergamin Filho, A. Diagrammatic scales for bean diseases: Development and validation. Zeitschrift fur Planzenkrankheiten und Pflanzenschutz, Sonderheft, v.104, n.4, p.336-345, 1997.

Oliveira, S.H.F.; Recco, C.A.V.; Oliveira, D.A. Efeito comparativo da aplicação de fungicidas por pivô central e método de aplicação convencional para controle de doenças e produtividade do feijoeiro. Fitopatologia Brasileira, Brasília, v.17, n.2, p.151, 1992a. 
Oliveira, S.H.F.; Recco, C.A.V.; Oliveira, D.A. Eficiência comparativa da fungigação e aplicação convencional de fungicidas no controle de oídio e mancha de alternária em feijoeiro. Fitopatologia Brasileira, Brasília, v.17, n.1, p.67-70, 1992 b.

Oliveira, S.H.F.; Recco, C.A.V.; Sugahara, E.; Oliveira, D.A. Avaliação comparativa da fungigação e aplicação convencional de fungicidas para controle de Sclerotinia sclerotiorum. Summa Phytopathologica, Jaguariúna, v.21, n.3/4, p.249-251, 1995.

Paula Júnior, T.J.; Zambolim, L. Doenças. In: Vieira, C.; Paula Júnior, T.J.; Borém, A. (eds.). Feijão: aspectos gerais e cultura no Estado de Minas. Viçosa: UFV, 1998. p.375-433.

Pinto, N.F.J.A.; Costa, E.F. Efeito da lâmina de água na aplicação de fungicida via aspersão convencional para o controle da brusone (Pyricularia oryzae) em arroz. Fitopatologia Brasileira, Brasília, v.17, n.2, p.185, 1992.

Pinto, N.F.J.A.; Costa, E.F.; Ribeiro, E.A. Aplicação de fungicida via água de irrigação por aspersão para o controle de ferrugem (Uromyces phaseoli) em feijoeiro. Fitopatologia Brasileira, Brasília, v.15, n.2, p.144, 1990.
Rocha, C.L.; Felippe, J.M.; Begliomini, E. Avaliação do epoxiconazole puro e em misturas no controle de doenças na cultura do feijão (Phaseolus vulgaris). Fitopatologia Brasileira, Brasília, v.24 (sup.), p.452, 1999.

Sartorato, A.; Rava, C.A. Controle químico da mancha angular do feijoeiro comum com aplicação de fungicidas via pivô central. Summa Phytopathologica, Jaguariúna, v.24, n.3/4, p.253-257, 1998.

Vieira, C. A cultura do feijão. Viçosa: UFV, 1978. 146p.

Vieira, R.F.; Paula Júnior, T.J. Semente: veículo de disseminação de patógenos. In: Vieira, C.; Paula Júnior, T.J.; Borém, A. (Eds.). Feijão: aspectos gerais e cultura no Estado de Minas. Viçosa: UFV, 1998. p.451-505.

Vieira, R.F.; Silva, A.A. Aplicação de defensivos agrícolas via água de irrigação por aspersão. In: Vieira, C.; Paula Júnior, T.J.; Borém, A. (Eds.). Feijão: aspectos gerais e cultura no Estado de Minas. Viçosa: UFV, 1998. p.267-323.

Vieira, R.F.; Sumner, D.R. Application of fungicide to foliage through overhead sprinkler irrigation - a review. Pesticide Science, London, v.55, p.412-422, 1999. 